\title{
El bileği kırıklarının ve yanlış kaynamalarının tedavisinde kullanılacak aynı anda redüksiyon ve tespite olanak veren bir eksternal fiksatör
}

\author{
An external fixator that is used in the management of \\ both reduction and fixation of wrist fractures and malunions
}

\author{
Ahmet Mehmet Demirtaş
}

Ortopedi ve Travmatoloji Uzmanı, Ankara

\begin{abstract}
Distal radius vücutta en sık kırılan kemiklerden olup, her yıl dünya üzerinde yüz binlerce kişinin el bileği fonksiyonlarının, ağrılı ve kısıtlı olmasına sebebiyet vermektedir. Kilitli distal radius plakları ve eksternal fiksatörler distal radius kırıklarının tespiti için kullanılan materyallerdir. Temel olarak yer değiştirmiş iki ya da daha fazla kemik parçasının anatomik olarak uygun pozisyonda K-telleri, eksternal fiksatör ya da metal (titanyum) plağın vidalar yardımı ile tutturulması prensibine dayanır. Eksternal fiksatörler ise kırık bölgesini açmadan kırığın her iki tarafındaki sağlam kemikten geçirilen en az iki adet vida veya K-teli yardımı ile reduksiyonun sağlanmasının ardından, eksternal fiksatör üzerindeki düzenek kullanılarak kırı̆̆ın sabitlenmesi prensibiyle çalışmaktadır.
\end{abstract}

Anahtar sözcükler: el bileği eklemi; distal radius kırıkları; redüksiyon; tespit

\section{Amerika Birleşik Devletleri Patent Enstitüsü'ne Başvuru Bilgileri[ ${ }^{[1]}$}

Başvuru bilgileri Tablo 1'de gösterilmiştir. ${ }^{[1]}$

Tablo 1. Başvuru bilgileri ${ }^{[1]}$

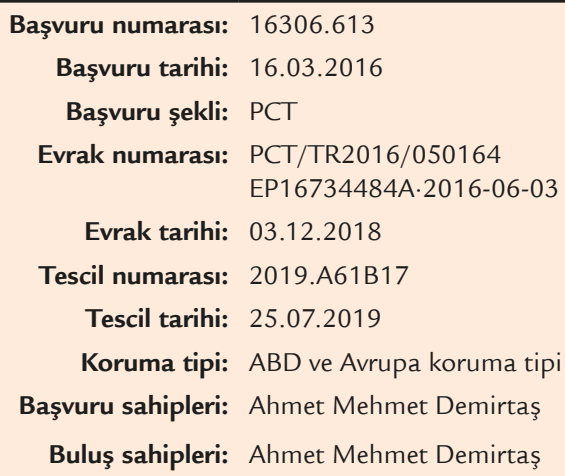

\begin{abstract}
The present invention relates to reduction and fixation of bone fractures of distal radius and wrist. The invention enables to mobilise the distal fragment in 3 planes and also to correct rotational deformity. The object of the present invention is to realize an external fixator which enables to reduce a fracture and at the desired position and fix the fracture. In case of unsuccessful reduction attempt for the second trial there is no need to dismount the fixator. Another object of the present invention is to realize an external fixator which enables to reduce a fracture in 3 dimensions and to correct the rotational deformity in a preferred degree. Another object of the present invention is to realize an external fixator which can practically be mounted to malunion zone and can be used for reducing in corrective osteotomy operations.
\end{abstract}

Key words: wrist joint; distal radius fractures; reduction; fixation

\section{PATENT BELGESi - No: 2019.A61B17 ${ }^{[1]}$}

Teknik Alan ${ }^{[1]}$

“Distal radius kırıklarında kırık parçaların düzeltilmesi redükte edilmesi ve tespiti için eksternal fiksatör tasarımı ile ilgilidir. Distal parçanın üç düzlemde kontrolü ve rotasyon kontroluna imkân vermektedir.”

\section{Önceki Teknik/Teknikler[1] \\ Eski teknik}

"Distal radius vücutta en sık kırlan kemiklerden olup, her yıl dünya üzerinde yüz binlerce kişinin el bileğinde ağrılı ve fonksiyonel olarak kısıtı bir el bileğine neden olmaktadır. Kilitli distal radius plakları ve eksternal fiksatörler bu kemik bölgesinin tespiti için kullanılan materyallerdir. Temel olarak iki ayrı kemik parçasının dışarıdan tellerle tutturulmasını takiben uygun pozisyonda metal (titanyum) plağın vidalar yardımı

- Iletişim adresi: Prof. Dr. A. Mehmet Demirtaş, İran Cad. No: 5/11 Kavaklıdere, Ankara Tel: 0532 - 2752383 e-posta: demirmeh@yahoo.com ORCID iD: 0000-0002-6877-0787

- Geliș tarihi: 25 Kasım 2020 Kabul tarihi: 9 Aralık 2020 
ile her iki kemiği uygun pozisyonda tutacak şekilde tutturulması prensibine dayanır. Eksternal fiksatörler ise, kırık bölgesini açmadan kırı̆̆ın iki tarafindaki kemiklerden geçirilen en az iki adet vida veya telin cihazın parçası olan bir ünitin içindeki deliklerde geçirerek bu ünitleri tek bir bar veya boru üzerinde kırık redüksiyonu (düzelmesi) sağlandıktan sonra somun veya sıkıştıııı vidalar yardımıyla sabitlemektedir.”

\section{Buluş ile elde edilen avantajlar ${ }^{[1]}$}

"1- Kırık parçalardan geçirilen tel veya vida yardımı ile kırığın tam redüksiyonu sağlanmaktadır.

2- Tespit edilen kırıkta radyolojik kontrol sonrası rotasyonel veya yertersiz redüksiyon varsa fiksatörü çıkartmadan optimum redüksiyon sağlanabilir.

3- Eğer kırık redüksiyonu için gerekirse distraktörler yardımı ile daha yüksek kuvvetler uygulanabilir.

4- Eğri kaynamış kırıkların tekrar kırılarak düzeltilmesi için yapılan düzeltici osteotomi girişimleri de bu fiksatörle osteotomiyi takiben istenilen pozisyon sağlanabilir.”

\section{Buluşun Kısa Tarifi[ ${ }^{[1]}$}

"El bileği travmalarında eksternal fiksatörler gerilmeye bağıı çıkan distrofi nedeniyle ilk çıktı̆̆ı zamana göre daha seyrek kullanılmaktadır.

Ligamentotaksis kavramı ile gererek redüksiyon ve tespit sağlamaktadır.
$\mathrm{Bu}$ fiksatör redüksiyonu gererek değil direk fragmanlara yerleşen birimleri üç düzlemde kontrol ve manüple edebilme imkânı vermekte, ayrıca rotasyonel düzeltmeyi de sağlamaktadır.

Tesbihten esinlenerek tasarlanan bu ünit, çelik bir tel üzerinde K-teli geçecek delikleri olan modüllerin olduğu, uzunluk düzeltmesi için bir teleskopik rod üzerinde ayrı bir ünit ile radius cisimine tespit edilen ve distraktör yardımı ile uzun eksende istenilen miktarda yer değiştimeye olanak sağlayan bir cihazdır. Bu ünitin kaydığı rod yuvarlak olduğu için aynı zamanda rotasyon da düzeltilebilir. Tasarlanan bu fiksatör sert plastikten olup radyolojik olarak kırık kaynaması daha rahat kontrol edilebilmektedir.

Çelik telin zamanla gevşeme ya da stabiliteyi azaltma riskine karşı modüller üzerinde bulunan deliklere yerleştirilecek olan omurga cerrahisinde kullanılan lale şeklindeki üstü açık tulip spinal vidalar gibi fazladan iki rod yerleştirmeye imkân verdiği için çerçeve etkisi ile çok stabil olmaktadır.

Kolay uygulanan, hem kırıkta hem de her türlü yanlış kaynama yani deformite düzeltmeye imkân vermesi ile de illizarov yönteminin avantajlarını da taşımaktadı."

\section{Buluşun Detaylı Açıklanması ${ }^{[1]}$}

“Buluş ve tekniğin uygulanışı Şekil 1-5’te izah edilerek gösterilmiştir.”

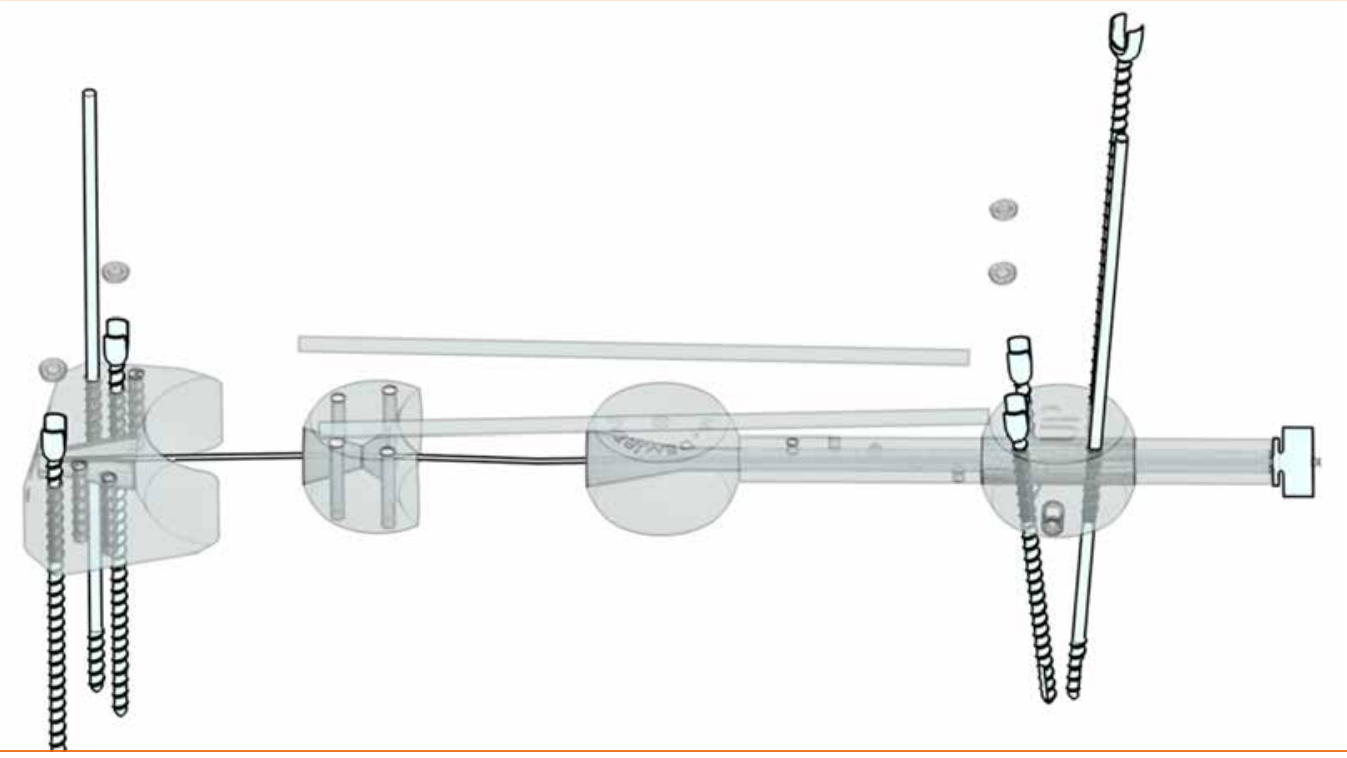

Şekil 1.

- Proksimal parça radiusa tespit edilir.

- Teleskopik rod ve üzerinde kayacak ünit içinden K-teli geçecek dört delik var. Bu ünit istenilen yerde rod vida ile sıkıştırılarak tespit edilir.

- Distal parça kırık fragmana tespit edilir.

- Içinden yivli K-telleri geçecek ünit; çelik telin geçtiği delik konik olup $15^{\circ}$ her yöne hareket imkanı verir ve aynı zamanda yüzeyi yuvarlak olduğu ve proksimal parçanın konveks yüzeyi ile eklem yaptı̆̆ için üç düzlemde oynayabilir ve sistem çelik tel gerildiği zaman stabil hale gelir.

- Çelik telin zamanla gevşeme ihtimaline karşı spinal cerrahide kullanılan tulip (lale) vida benzeri yivli vidalar aynı yiv aralığında tasarlanmış deliklerden geçerek fiksatörün ciltten olan mesafesini korumuş olur. Bu vidalar ince bir rod ile tespit edilerek çerçeve etkisi yaparak stabiliteyi güvenli hale getirir. 


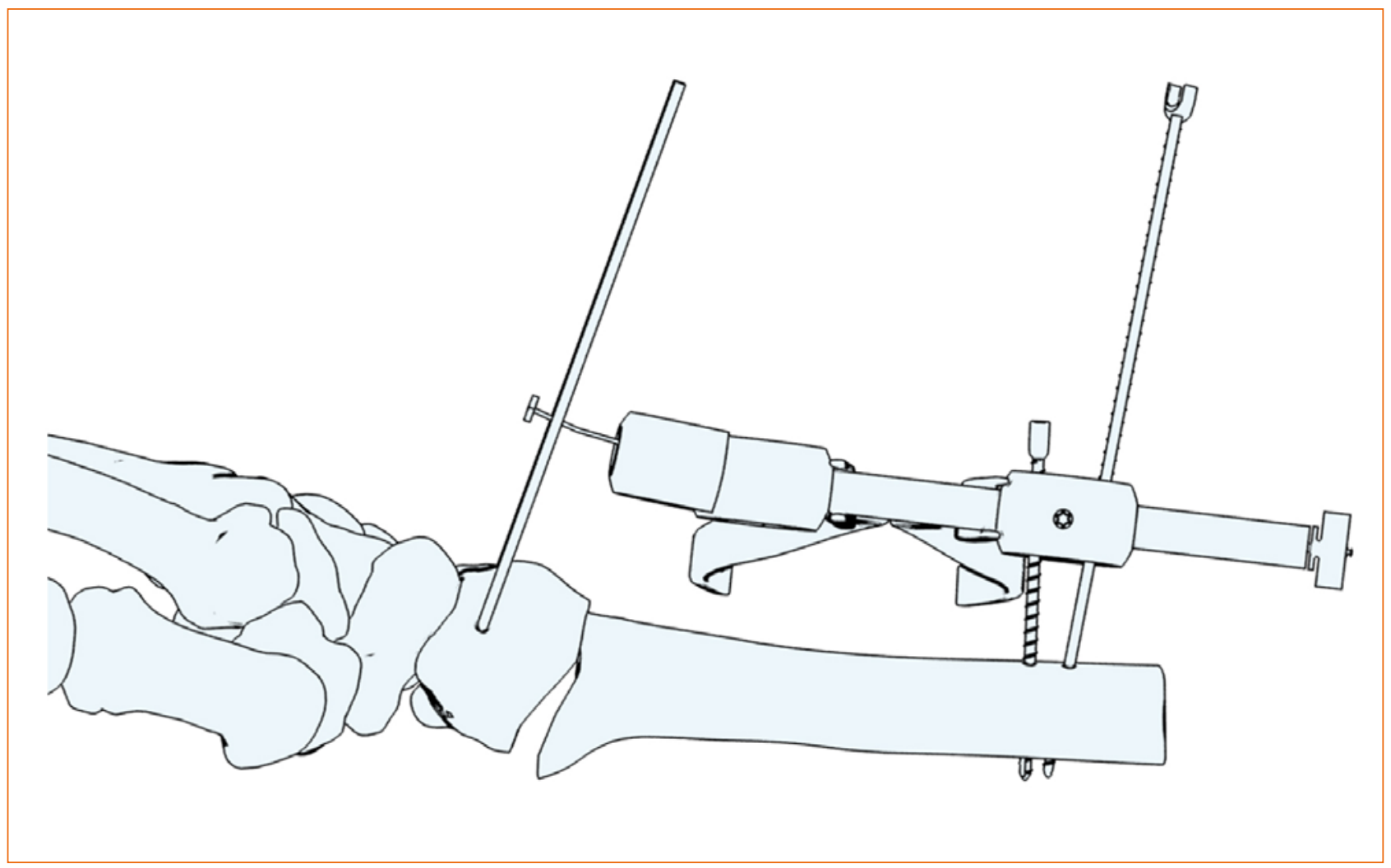

Şekil 2. Fiksatörden K-telleri geçirilmiştir. K-telleri bir joy stick gibi kullanılarak fragman kontrolü ve redüksiyon sağlanıyor ve bir distraktör yardımıyla da uzunluk düzeltmesi să̆lanıyor.

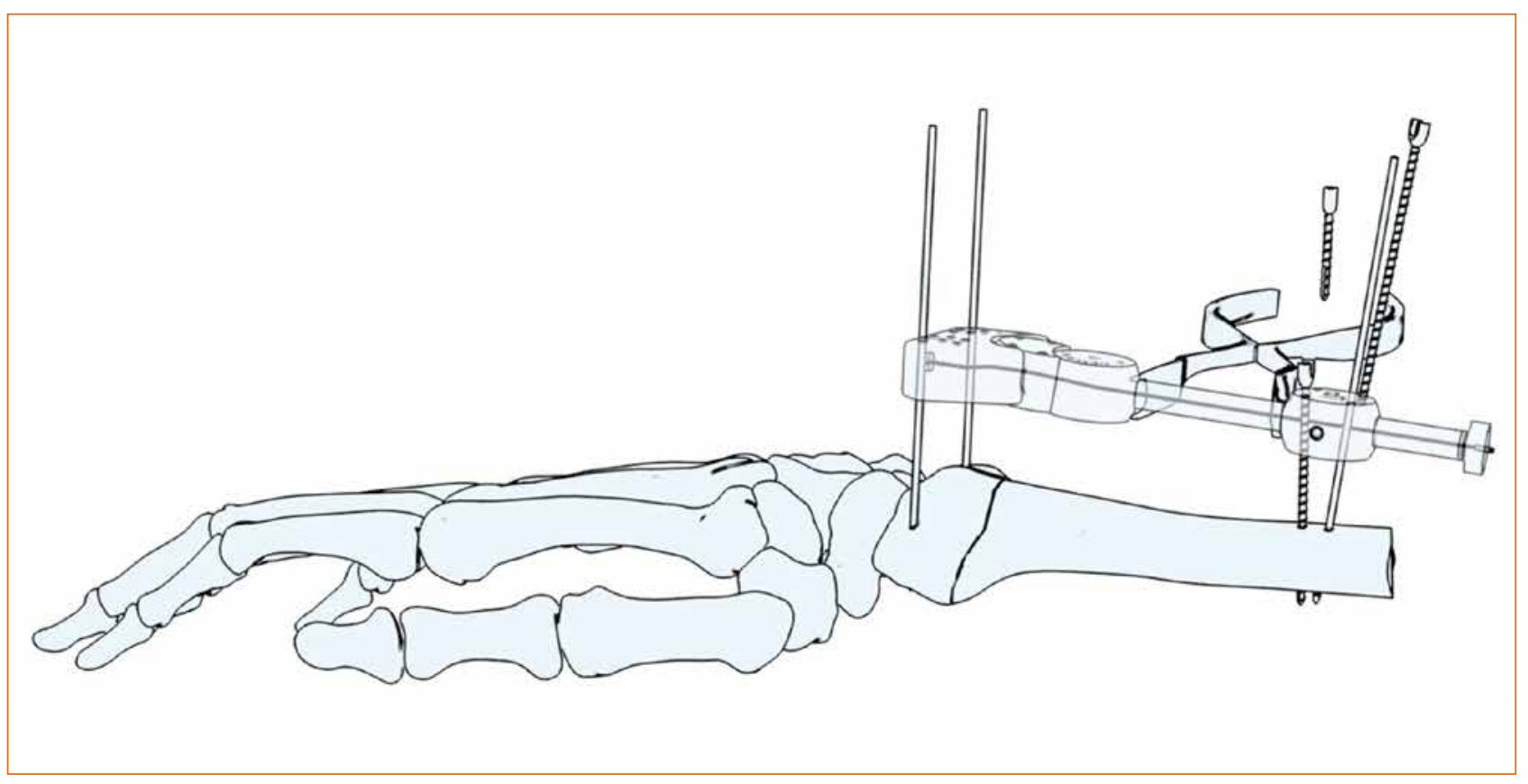

Şekil 3. Kırı̆̆ın redükte hali. 


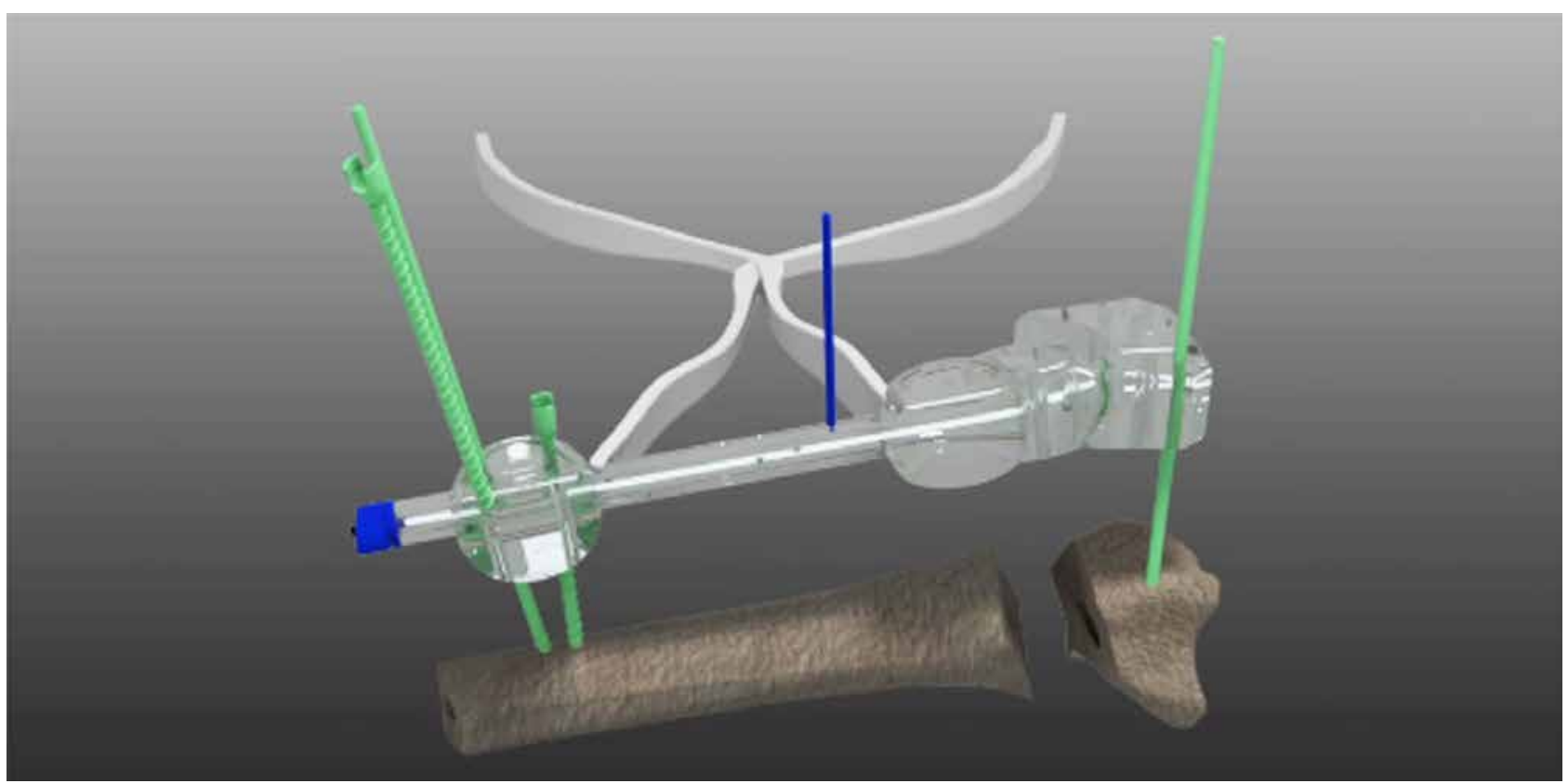

Şekil 4. Teleskopik rot üzerindeki deliklere yerleştirilen ince bir kılavuz tel referansı ile rotasyon düzeltmesi yapıllyor.

Bu fiksatör yanlış kaynama düzeltilmesi için yapılacak düzeltici osteotomiler için yeterli uzunluk ve distal parçanın pozisyonunu kontrol ederek amaçlanan pozisyonu sağlayabilir. Bu işlem ayrıca bilgisayar yardımlı üç düzlemde gerekecek olan düzeltme miktarı hesaplanarak da yapılabilir.

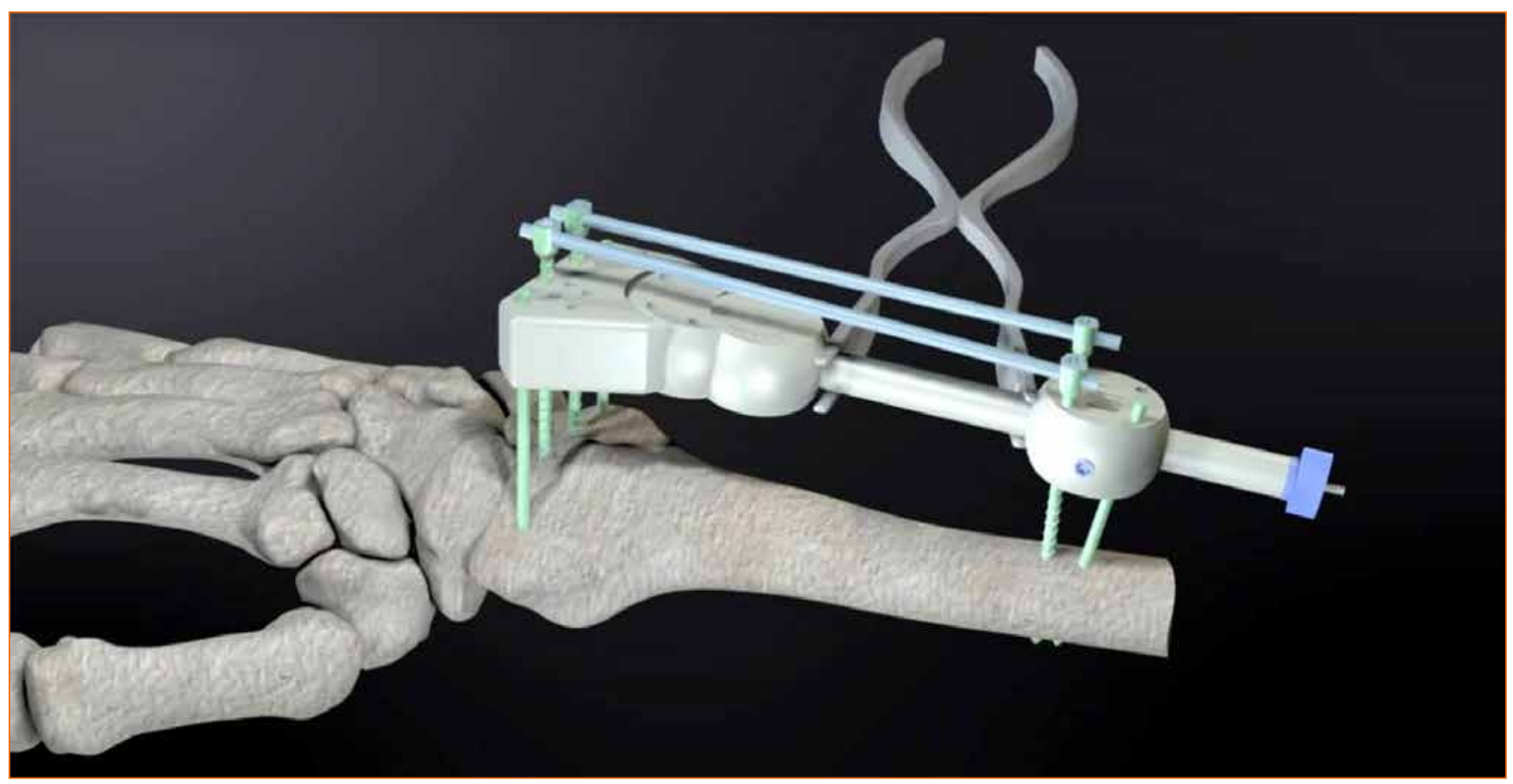

Şekil 5. Kırı̆̆ın redükte edilmiş ve rodlarla tespit edilmiş hali.

\section{KAYNAK}

1. United States Patent Application Publication; PCT No: PCT/TR2016/050164 